\title{
A CONSTRUÇÃO DISCURSIVA DE IDENTIDADES SOCIAIS NO GÊNERO NOTICIOSO ${ }^{1}$
}

\author{
(The discursive construction of social identities \\ in news reports)
}

\author{
Herimatéia Pontes ${ }^{2}$ \\ (Universidade Federal do Piauí-UFPI)
}

\begin{abstract}
Taking into account the social nature of discourse, the construction of social identities as a one of the ideological effects of discursive practices and the role of media in the construction/representation of social reality, this paper analyses the linguistic and discursive strategies used by news writes to construct the social identities of victims and criminals in news reports resulting in death. Our theoretical and methodological framework is informed by the discourse social theory of Fairclough (1989, 2001, 2003) which adheres to Critical Discourse Analysis.
\end{abstract}

Keywords: Critical Discourse Analysis, representation, social identities and media.

\section{RESUMO}

Tendo em vista a natureza social do discurso, a construção de identidades sociais como um dos efeitos ideológicos da prática discursiva e o papel da mídia na construção/representação da realidade social, este trabalho se propõe a analisar as estratégias lingüístico-discursivas utilizadas na produção do texto noticioso para

1 Artigo baseado na dissertação intitulada $A$ construção de identidades sociais de vítimas e criminosos no relato de crimes de morte na mídia impressa, defendida em junho de 2004 para obtenção do título de Mestre no Programa de Pós-Graduação em Letras/Linguística da Universidade Federal de Pernambuco (UFPE).

2 Doutora em Letras/Linguística pela Universidade Federal de Pernambuco (UFPE), com Estágio Sanduíche em Lancaster University, Inglaterra, é Mestre em Linguística e Licenciada em Letras (Licenciatura em Português / Inglês) pela mesma IES. 
construir identidades sociais de vítimas e criminosos nos relatos de crime de morte. Na abordagem da Análise Crítica do Discurso como método de pesquisa social, nos baseamos na teoria social do discurso de Fairclough (1989, 2001, 2003).

Palavras-chave: análise crítica do discurso, representação, identidades sociais, mídia impressa.

\section{Introdução}

Problemas sociais em nosso mundo contemporâneo estão inextricavelmente relacionados ao discurso. Dos relatos na mídia impressa sobre as manifestações da violência, tais como os crimes de morte, aos discursos públicos sobre corrupção política, os problemas sociais são expressos pelo discurso que modela, e de certo modo, naturaliza a definição destes problemas, bem como, pode reagir a esta naturalização, promovendo mudança social.

Neste ínterim, chamamos atenção especial para o discurso da mídia, pelo importante papel que desempenha na representação da realidade social ao (re) produzir, (des) legitimar e mediar ideologias dominantes, bem como o exercício de poder de grupos sociais sobre outros. Fairclough (1989:49) ressalta que "a natureza das relações de poder que atuam nesse discurso [da mídia] nem sempre é tão clara e há razões para vê-lo como envolvendo relações ocultas de poder”. Deste modo, tem se tornado objeto inesgotável de estudos no campo da Análise Crítica do Discurso, doravante ACD em sua agenda explicitamente sócio-política, sob diferentes perspectivas teóricas (cf. por exemplo, Fairclough 1995, Kress \& Van Leeuwen 1996, Van Dijk 1987 e Garrett \& Bell 1998).

Com uma análise crítica do discurso buscamos compreender como se dá a representação da realidade social pelo discurso da mídia, em termos da construção de identidades sociais de vítimas e criminosos, como prática social e ideológica que se manifesta discursivamente através de categorias linguísticas e discursivas nos relatos de crimes de morte. Uma notícia ou reportagem ao mesmo tempo em que é produzida também 
constrói a representação de uma realidade e, em último caso, determina o que se percebe como cultura, interesses e preferências de um povo.

Pela limitação do espaço e natureza deste trabalho, faremos uma breve exposição dos conceitos de gênero textual de discurso e identidade social (segunda seção) bem como das bases teóricas e metodológicas que sustentam nossa análise e nos situam na ACD (terceira seção). Em seguida, ilustraremos as categorias de análise descobertas em nossa pesquisa, através de amostras concretas de nosso corpus (quarta seção). Posteriormente, trataremos das considerações finais deste trabalho.

\section{Discurso e Identidade Social}

Identidades sociais são construtos sócio-discursivos. Através do discurso, os atores sociais constroem e representam a sua realidade social, a si mesmos e aos outros num confronto identitário. Como aponta Fairclough (2001:91), discurso é um modo de ação social em que significados são negociados e compartilhados em sociedade nas práticas discursivas situadas historicamente. Isto nos faz perceber a interação social como o locus legítimo para esse processo bem como unidade de análise a ser considerada. Fazendo referência a Shotter, Lopes (2002:31) aponta para o fato de que "a análise da dinâmica da interação torna possível compreender quem tem responsabilidade por qual atividade na construção dos significados de qualquer comunicação”. Conseqüentemente, tanto a análise dos diferentes meios usados pelos participantes para atuar no mundo quanto à compreensão dos significados construídos e compartilhados no processo discursivo são importantes.

Em linhas gerais, os conceitos e pressupostos teóricos que dão subsídios para nossa reflexão e análise da construção de identidades no e pelo discurso são os seguintes:

a. Gêneros textuais - Percebemos gênero como evento comunicativo e prática sócio-histórica, e não apenas como forma estrutural ou lingüística, pois existem na medida em que as 
atividades comunicativas humanas existem. Como produtos da coletividade, "os gêneros contribuem para ordenar e estabilizar as atividades comunicativas do dia-a-dia. São entidades sócio-discursivas e formas de ação social incontornáveis em qualquer situação comunicativa” (Marcuschi 2002:19). Nós nos comunicamos através de gêneros textuais.

Como prática social, o discurso da mídia impressa se materializa em diversos gêneros textuais que circulam principalmente em dois suportes, os jornais e as revistas, amplamente consumidos pela população. Destes gêneros, destacamos a reportagem e a notícia como prototípicos.

O gênero noticioso é o mais popular porque notícias são histórias e por essa razão, são mais atraentes, mais fáceis de serem produzidas, uma vez que ouvimos e contamos histórias desde a nossa tenra infância. Por outro lado, as notícias são entretenimento (cf. por exemplo, Dias 1996). Nas bocas das pessoas, essas histórias são retomadas, reproduzidas, avaliadas, investidas de novos significados. Com isso, entendemos que as notícias não são eventos neutros nem tão pouco, a representação objetiva dos eventos, mas, são construtos sociais e culturais que desempenham um importante papel social, político e educacional na constituição da sociedade. Como afirma Caldas-Coulthard (1997:11), ao serem expostas às notícias, as pessoas fazem conexões e tentam entender e explicar como eventos reportados na media se relacionam à sociedade como um todo.

b. Discurso - A natureza social do discurso é a sua característica mais essencial na medida em que (i) usamos a linguagem quando interagimos com outras pessoas - natureza dialógica do discurso (Bakhtin 1992); (ii) participamos de uma sociedade - socialização lingüística (Ochs 1996); e (iii) construímos o mundo, especialmente em termos de identidades sociais, através dos significados indexicais (Ochs 1996, Duranti 1997, etc.). Diante disto, entendemos discurso como apresentado por Fairclough (2001) em sua teoria social de discurso, como 
sendo simultaneamente (i) um texto lingüístico, oral ou escrito, (ii) prática discursiva (produção e interpretação de texto) e (iii) prática sócio-cultural.

A noção de discurso de Fairclough (2001:90-91) consiste no "uso da linguagem como forma de prática social e não como atividade puramente individual ou reflexo de variáveis institucionais”, ou ainda mera representação de mundo. Discurso é ação que as pessoas exercem sobre si e sobre os outros, que está em relação dialética com a estrutura social, posicionado em relação a lutas hegemônicas e aberto para ser investido ideológica e politicamente, uma prática que constrói e significa o mundo através da construção de identidades sociais, das relações sociais e dos sistemas de conhecimento e crença.

c. Identidade sociais - Analisar a construção das identidades sociais como um dos efeitos do discurso constitui uma importante ferramenta para estudar a mudança social, porém, definí-la não é tarefa fácil. Isso se dá pelo fato de que há uma multiplicidade de questões a ela relacionadas, principalmente, de natureza epistemológica e teórico-metodológica. Signorini 1998, por exemplo, reúne uma série de trabalhos sob diferentes perspectivas com o objetivo de gerar mais reflexão sobre essas questões ainda não fechadas.

Em virtude disso, tomamos os seguintes pressupostos teóricos sobre identidade:

(i) o conceito de identidade não é um todo estável e homogêneo, mas uma produção/construção em "permanente estado de fluxo” (cf. Rajagopalan 1998:21-42). Identidade não é fixa nem categórica;

(ii) a identidade de um indivíduo se constrói na língua e através dela no jogo da interação social (cf. Signorini 1998:41-42, Gumperz 1982), porém, a relação linguagem-identidade raramente é explícita; 
(iii) os processos de auto e hetero-atribuição de identidade social emergem no contexto interacional. Identidade é um construto social (cf. Ochs 1993:288); e

(iv) a construção de identidades é um fenômeno essencialmente ideológico (cf. Fairclough 2001).

Por sermos sujeitos históricos, sociais e culturais, nossa identidade não é estática, mas, processual, ou seja, é construída no processo das atividades sócio-discursivas das quais fazemos parte, e dessas atividades provêm uma multiplicidade de papéis sociais que se articulam. Entendemos como Ochs (1996:410) que a noção de identidades sociais engloba todas as dimensões da persona social incluindo propriedades como papéis (estudante, mãe, filha, professora, etc.), relações (de parentesco, profissionais, etc.), identidade de grupo (gênero, idade, etnia, religião, etc.), posição (titulação, status profissional, classe social etc.), dentre outros. Identidade social é uma das dimensões sociais ativadas pelos participantes para fazer parte de uma dada situação comunicativa e está diretamente relacionada aos papéis e ações sociais atribuídas e desempenhadas por estes, bem como às suas posturas afetivas e epistêmicas.

\section{ACD: teoria e método}

A ACD é uma abordagem relativamente recente de análise do discurso que disponibiliza teorias e métodos para o estudo empírico das relações entre discurso, sociedade e cultura em diferentes domínios sociais, não sendo, portanto, homogênea, pois congrega várias abordagens em torno de um projeto comum e multidisciplinar (cf. por exemplo, Fairclough, Wodak, Van Dijk, Kress, dentre outros)

Crucial para a ACD é a consciência explícita do seu papel na sociedade, por isso se posiciona como politicamente engajada ao definir seus objetivos em termos políticos, sociais, culturais e éticos. Seu comprometimento está em causar efeitos na prática social e relações 
sociais, como, por exemplo, contribuir para o desenvolvimento do ensino através da consciência crítica dos usos da linguagem (Clark 1996), para a elaboração de parâmetros para o uso não sexista ou racista da linguagem (van Dijk 1987 a), em propostas para facilitar a compreensão do papel do discurso na (re) produção da desigualdade social pelo abuso de poder e dominação ou em propostas para investigar o funcionamento do gênero noticioso na construção discursiva de identidades, como no nosso caso.

De modo geral, os princípios que regem essa abordagem do discurso podem ser resumidos como abaixo (cf. Fairclough \& Wodak 1999, Fairclough 2001, 2003, Philips \& Jorgensen 2002, Wodak apud van Dick 2004, dentre outros)

- A ACD estuda problemas sociais via discurso;

- A ACD é abordagem crítica que está politicamente comprometida com a mudança social;

- A análise do discurso é descritiva, interpretativa e explanatória, demonstrando assim, seu caráter científico;

- O uso da linguagem deve ser analisado empiricamente no seu contexto social;

- As relações de poder são discursivas

- O discurso é histórico, funciona ideologicamente, sendo uma forma de ação social; e

- O discurso está em relação dialética com a estrutura social e com outras práticas sociais construindo assim a sociedade e a cultura através de identidades sociais, relações sociais e sistemas de conhecimento e crença.

Este conjunto de princípios aponta para a linguagem como prática social, o texto como produto social, os usuários lingüísticos como diferentes e diferencialmente localizados e os significados como produtos das relações sócio-políticas. A ACD é, portanto, uma teoria da ação, cujo comprometimento é com a pesquisa crítica e politicamente envolvida com a mudança social. 
No paradigma teórico-metodológico da ACD, destacamos as postulações de Fairclough e sua teoria social do discurso. ${ }^{3}$ Este autor formulou um modelo conceitual e analítico para analisar o discurso como prática social. Seu modelo integra diferentes conceitos em uma abordagem tridimensional do discurso, cujo interesse está em verificar a mudança nas sociedades contemporâneas pelo discurso, pois a mudança na linguagem e a mudança sócio-cultural estão intrinsecamente relacionadas. Deste modo, Fairclough entende que o discurso é fundamental para a construção do mundo social, sendo um dentre muitos aspectos da prática social.

Fairclough (1998:144) concebe três diferentes, mas, interdependentes tipos de análise que relacionam as práticas sociais e culturais a propriedades dos textos. São eles:

- a análise dos textos (orais e escritos);

- a análise da práticas discursivas que dão origem a esses textos e envolvem a sua produção e consumo; e

- a análise das práticas sociais e culturais que enquadram, situam, moldam os textos e práticas.

Deste modo, a característica principal da proposta analítica deste autor é mostrar que textos e sociedade são mediados pelas práticas discursivas. Ele considera que a análise da prática discursiva é complexa, pois abrange diferentes tipos de análise, incluindo aspectos discursivos dos processos institucionais (por exemplo, práticas de produção de notícias) bem como os aspectos sócio-cognitivos do processamento do discurso. Porém, seu interesse está na intertextualidade, ou seja, como na produção e no consumo (recepção e interpretação) de textos as pessoas usam, dispõem de outros textos que lhe são culturalmente disponíveis.

3 Cf. a apresentação e o desenvolvimento da teorização sobre o discurso de Fairclough em algumas de suas obras tais como Language and power (1989), Discourse and social change (1992b), Critical discourse analysis (1995 $)$ Media discourse (1995b), Discourse in late modernity (1999), New labour, new language? (2000) e Analysing discourse: textual analysis for social research (2003). 
Isto se dá pela combinação de elementos de diferentes discursos no uso concreto da linguagem que podem mudar tanto os discursos individuais quanto o mundo social e cultural. Segundo Philips \& Jorgensen (2002:7), "através da análise da intertextualidade, podemos investigar tanto a reprodução dos discursos (...) quanto a mudança discursiva através de novas combinações de discurso”. Essas mudanças apontam, portanto, para a percepção de que o mundo social está mudando e como isso está acontecendo.

Como o próprio Fairclough (2001) sugere, seu método é apenas um modelo para a análise crítica. Dispor do modelo ou de alguns dos seus elementos vai depender da escolha do analista de acordo com o problema a ser investigado e os questionamentos levantados. Não há, portanto, um modelo rígido, linear e $100 \%$ eficaz para análise. Com isto, não pretendemos cobrir os diferentes aspectos do modelo tridimensional, mas nos deter na análise das categorias lingüístico-discursivas que contribuem para a construção das identidades sociais enquanto um dos efeitos ideológicos e hegemônicos do discurso, situada na prática social, no gênero noticioso.

Em linhas, os procedimentos metodológicos e analíticos que orientaram nosso trabalho podem ser resumidos como abaixo:

- Para tratar da representação dos atores sociais, elegemos previamente em van Leeuwen (1997) as categorias de nomeação, categorização e distribuição de papéis e em Fairclough (2003), a modalização e sua relação com a avaliação (a qual preferimos chamar de modalização avaliativa) porque é mais frequente no corpus, como amostra do processo de produção das notícias e reportagens sobre crimes de morte.

- No que diz respeito às categorias analíticas que investigamos, ressaltamos que:

(a) usamos o termo "categorias" num sentido mais abrangente para especificar as categorias analíticas do nosso trabalho, citadas acima, como também num sentido mais restrito, significando classificação, ou seja, subtipos da categorização (ex: 
classe social, opção sexual, política ou religiosa, função ou ocupação profissional, etc.);

(b) o elemento centralizador dessas categorias analíticas é o conceito de "ator social" (Goffman 1998) e não um conceito linguístico como o de "grupo nominal", por exemplo.

- Como o interesse deste estudo se concentra na mídia impressa, selecionamos como veículos-alvos um jornal diário (a Folha de São Paulo) e três revistas semanais (Veja, Isto É e Época). Os critérios usados para esta escolha foram a natureza dos textos, ou seja, textos escritos, e o fato destes veículos serem bastante representativos na mídia impressa nacional, pelo seu grande consumo e circulação ${ }^{4}$.

- O corpus coletado consistiu de 25 amostras de notícias e reportagens sobre crimes de morte que ocorreram em território nacional, uma vez que nos interessa a verificação de possíveis mudanças nas práticas sociais da sociedade brasileira.

- Devido à quantidade de notícias e reportagens selecionadas, não pretendemos fazer um estudo quantitativo, mas qualitativo, a partir da representatividade das amostras que buscamos na variação dos veículos.

- Seguimos o seguinte roteiro na análise dos dados: o: (a) agrupamento e classificação dos crimes por tipo e causa mortis; (b) verificação de tendências temáticas desses crimes (ex: filhos/ as que matam familiares após consumo de drogas, sequestros seguidos de morte, assassinatos de autoridades públicas como

4 É relevante mencionar dois aspectos quanto aos veículos selecionados: em primeiro lugar, reconhecemos a diferença do posicionamento político-ideológico nestes veículos, por isso a importância de um estudo voltado para cada um deles. Contudo, este não é o nosso propósito neste trabalho. Em segundo lugar, independente do veículo impresso, se jornal ou revista, a especificidade de nossa análise está em mostrar a não neutralidade e imparcialidade da mídia na representação da realidade social. $\mathrm{O}$ próprio fato a ser noticiado, o modo como será relatado, as categorias linguísticodiscursivas convencionadas e o próprio gênero noticioso são escolhas que resultam de um processo sócio-histórico e atendem às expectativas da sociedade, ao passo que também conduzem a nossa interpretação e formam opinião. 
vingança ou queima de arquivo, etc.), lembrando o que Fishman (1978) denominou de "ondas de crime"; (c) leitura das amostras para verificação das categorias em evidência nos textos; (d) comparação das amostras para identificação de regularidades, padrões ou sub-tipos das categorias destacadas; e (e) interpretação dos dados.

\section{Análise das categorias representacionais na construção de identidades sociais no gênero noticioso}

A questão geral que norteia este estudo é a preocupação em perceber os diversos modos pelos quais os atores sociais podem ser representados no discurso da mídia impressa e que efeitos de sentido resultam das escolhas representacionais que fazemos na materialidade da língua. Especificamente, no recorte desta análise, meu interesse está em ver como essa representação se dá em termos de duas categorias principais de atores sociais no relato de crimes de morte: as vítimas e os criminosos. A quem é dado mais proeminência e por quê? Quem é nomeado e como isso ocorre? Que classificações ou categorias são consideradas relevantes para identificar os outros? Quem recebe papéis ativos? Quem é paciente e recebe os efeitos de uma ação como objeto ou beneficiário? Quem é avaliado positiva ou negativamente em relação à dada ação e como isso ocorre? Essas escolhas são socialmente significantes na representação dos atores sociais (grupos, comunidades)? Tentaremos, portanto, investigar questões dessa natureza.

A questão da representação é tanto gramatical quanto sóciosemântica. Isto se explica pela biunicidade da língua, resultando em uma não co-referência exata entre categorias linguísticas e sociológicas. Um exemplo disso é a representação da agência, ou seja, nem sempre a agência sociológica se realiza através da agência linguística, resultando assim em uma incongruência entre papéis linguísticos e sociais. Por 
exemplo, em ‘Ela [a vítima] perdeu a vida' e 'O juiz morreu no hospital', as vítimas são acionadas gramaticalmente como agentes dos processos verbais introduzidos por 'perdeu' e 'morreu' quando na verdade, são sociologicamente pacientes desses processos, pois foram vitimados pelos criminosos, agentes de fato.

Por outro lado, o problema da representação é sócio-semântico porque os significados indexicais são inerentes à cultura em si e não a língua, podendo ser associados a uma semiótica diferente. Um exemplo disso são as categorias que consideramos importantes socialmente para identificar pessoas (faixa etária, classe social, nível de escolaridade, profissão, etc.). Em 'A estudante Gabriela Prado Ribeiro, filha única, 14 anos, foi atingida num tiroteio entre bandidos e policiais (...)', podemos observar algumas dessas categorias consideradas importantes para identificar pessoas, a saber, a nomeação pelo nome próprio (Gabriela Prado Ribeiro), a classificação pela ocupação (estudante), a idade (14 anos) e a identidade relacional (filha única).

Deste modo, as realizações ou categorias linguístico-discursivas que mais se destacam no relato de crimes de morte para identificar vítimas e criminosos são: a nomeação, a categorização, a distribuição de papéis e a modalização. Com isso, procuramos verificar, em termos mais abrangentes, como as práticas sociais que produzem representações se transformam em discursos sobre essas mesmas práticas.

Convém apresentarmos e exemplificarmos brevemente cada uma das categorias analíticas que estudamos, a partir de amostras do nosso corpus:

- Nomeação - Os atores sociais podem ser representados pelo nome para sinalizar uma identidade única. Nomear é uma poderosa estratégia ideológica que pode mostrar os diferentes modos pelos quais percebermos e diferenciamos os outros. Em suas reflexões sobre a nomeação como poder simbólico, Bourdieu (1987:142) a considera como um dos modos elementares de diferenciação, de produção e imposição de sentidos (senso comum), de representação objetiva do mundo social. 
A imprensa escrita, por sua vez, enquanto aparelho ideológico não está fora dessa realidade. Nas narrativas noticiosas, a nomeação das vítimas e criminosos torna-se um importante ponto de identificação para o leitor.

Observamos que na representação dos atores sociais pela nomeação, a realização típica se dá através de nomes próprios acrescidos de outras informações consideradas relevantes culturalmente pelo autor na identificação desses atores. Isso é reflexo das práticas sociais nos textos, mostrando que as nomeações quase nunca acontecem sozinhas porque nossa sociedade identifica pessoas e grupos de determinado modo, como vemos nos exemplos abaixo:

Ex 1: (...) a fonoaudióloga Márcia Maria Lopes Coelho Lyra (...)

Ex 2: O líder sem-terra Gilson de Souza Lima (...)

Ex 3: (...) Ele e seu comparsa, Marcelo Melo Gonçalves dos Santos (...)

Ex 4: (...) o estudante Gustavo Napolitano (...)

O conjunto vasto de informações acrescidas aos nomes próprios são recursos que enriquecem e de certo modo categorizam as identidades sociais dos atores. Muitas vezes ocorre que tais informações podem substituir o nome próprio como forma de referência carregada de significações, sobretudo quando um ator social ocupa certa posição ou desempenha determinada função social.

É importante considerar que a substituição do nome próprio por outras formas de nomear, como identificaremos a diante, pode ocorrer ou para chamar atenção para determinado aspecto da identidade social dos atores ou como apenas um modo de progressão referencial no texto para evitar repetições. Contudo, acreditamos que a escolha por determinado tipo de referência, neste caso, o modo como os atores são nomeados, 
não é uma escolha inocente, mas traz um sentido. Por exemplo, em 'a fonoaudióloga Márcia Maria Lopes Coelho Lyra' [T 2], a informação importante é dada quanto à profissão. A vítima não é simplesmente uma mulher, mas uma mulher que tinha uma carreira profissional. Já em 'o líder sem-terra Gilson de Souza Lima' [T 4], a vítima não é apenas mais um trabalhador do campo que foi morto, ele era um líder sem-terra. A escolha por nomeá-lo pela atividade que exercia traz uma conotação política.

Isso nos faz pensar no fato de que a maioria desses recursos outros usados para nomear, tanto nomeiam quanto categorizam os atores sociais, ou seja, eles se fundem e se confundem, com exceção dos nomes próprios e idade.

Vejamos, por exemplo, a estratégia de nomeação pela identificação da condição social marginal ou estigmatizada.

Ex 5: (...) as ordens emitidas ao final da operação que culminou na morte de 19 sem-terra em Eldorado dos Carajás (...)

Ex 6: A idéia era chutar o mendigo (...).

Ex 7: No dia seguinte souberam que o índio caingangue (...).

Neste tipo de nomeação, notamos que ela ocorre, principalmente, para identificar atores que foram vitimados. Talvez essa forma de nomear relacione o crime e a situação de exclusão em que estas pessoas se encontravam. É o que nos mostram os exemplos: "19 sem-terra”, “o mendigo" e "o índio caingangue".

- Categorização - Os atores sociais podem ser representados também em termos de identidades e funções que partilham com outros no processo das interações sociais, dependendo do papel dos indivíduos ou grupos nas estruturas de poder (Van Leeuwen 1997, Fairclough 2003). Ocorre às vezes que 
a distinção entre nomeação e categorização torna-se difícil. Estes atores podem ser identificados individualmente, como por exemplo, a mãe, a vítima ou enquanto grupos, como por exemplo, as mães, as vítimas. As formas como categorizamos nosso mundo social demonstram nosso modo de organização e percepção das coisas bem como o que consideramos como valores desejáveis e indesejáveis em nossa sociedade. Contudo, estas categorias são histórica e culturalmente variáveis. Algumas delas estão necessariamente ligadas aos papéis sociais que desempenhamos em dada situação, não sendo, portanto, fixas ou permanentes. É o caso, por exemplo, do status profissional de um indivíduo que muda na medida em que muda de profissão.

Categorizar ou classificar atores sociais em grupos distintos mostra, basicamente, como uma dada sociedade ou cultura diferencia classes de pessoas, representando, portanto, uma forma de poder e controle social. Bourdieu (1987:142) considera que o trabalho de categorização

faz-se sem interrupção, a cada momento da existência corrente, a propósito das lutas que opõem os agentes acerca do sentido do mundo social e da sua posição nesse mundo, da sua identidade social, por meio de todas as formas do bem dizer e mal dizer, da bendição ou da maldição e da maledicência, elogios, congratulações, louvores, cumprimentos ou insultos, censuras, críticas, acusações, calúnias, etc. Não é por acaso que katègorein [termo grego] de que vem nossas categorias e nossos categoremas, significa acusar publicamente.

Diante do exposto, vem o questionamento: temos identidades múltiplas por trás dos papéis múltiplos que desempenhamos, dependendo das interações que travamos, ou nossa identidade é a soma de todos esses papéis que aprendemos a desempenhar socialmente? Apesar de nosso objetivo aqui não ser a resolução deste problema, acreditamos que identidade social é formada por um feixe de traços distintivos, que 
constituem a persona social, tais como, sexo, opção sexual, profissão, identidade relacional, etc.

Vejamos, por exemplo, como ocorre a categorização pelo papel de gênero social.

Ex 8: Luciana aparecida Vieira Pinto tinha 92 anos, era professora aposentada, possuía filhos e netos e vivia sozinha, escoltada por três empregadas contratadas pela família bem de vida de São José do Rio preto, no interior paulista.

Ex 9: Na sexta-feira 24, ele [Farah, o criminoso] trabalhou até seis horas da tarde. Depois que sua secretária e também o último paciente do dia tinham saído, o interfone tocou. Era sua examante $_{2}$ a dona-de-casa Maria do Carmo Alves de 46 anos.

Ex 10: Na madrugada de terça-feira, o engenheiro Waldo de Carvalho Wunder, 57 anos, assassinou sua mulher e as duas filhas, enquanto dormiam.

Essa classificação chama atenção especial para o papel social da mulher e como é representada na mídia impressa. Geralmente, os personagens femininos são descritos mais em termos de sua vida privada, ou seja, pelo papel sexual ("mulher de", “ex-amante”) ou funcional ("mãe”) apontando para relações de família, especialmente no seu relacionamento com um homem, do que em termos do seu papel profissional ou vida pública. Isso demonstra que a mídia impressa, como um instrumento de reprodução cultural envolvida com estruturas de poder, reflete valores sobre o mundo. Esses valores continuam refletindo e reproduzindo preconceitos e estereótipos sociais enquanto construções cognitivas naturalizadas na sociedade. Deste modo, o personagem masculino continua tendo destaque, evidência.

$\mathrm{Na}$ análise do corpus, dos 25 crimes abordados, mulheres são vitimadas em 09 textos, enquanto em 2, elas são criminosas. Por 
outro lado, homens são vítimas em 15, e criminosos explícitos ou subtendidos em 24. Essa proporção dá, portanto, mais evidência aos atores masculinos. Contudo, o que podemos inferir desses números? Acredito que esses números não representam a realidade em que muitas mulheres são vitimadas e sofrem vários tipos de violência. Será que a escolha dos crimes em que as vítimas ou até mesmo criminosos são atores masculinos não perpetua e legitima o status quo, em que homens estão ligados a estruturas de poder, inclusive o poder de representação na mídia impressa, enquanto as mulheres continuam com um acesso mais restrito às estruturas de poder e menos representatividade?

$\mathrm{O}$ fato é que homens e mulheres são tratados linguisticamente como categorias diferentes nas notícias, e isso não muda no relato de crimes de morte, refletindo assim, como a sociedade trata os gêneros sociais. Como aponta Caldas-Coulthard (1997:101), ignorar a reprodução assimétrica de poder entre os gêneros nas notícias tende a reforçar os estereótipos. Por outro lado, a consciência desta assimetria permitirá mudar as práticas discriminatórias as quais somos expostos diariamente, inclusive nos textos noticiosos.

- Distribuição de papéis - Considerar os papéis desempenhados em representações pelos atores sociais é um aspecto bastante significativo no trabalho de linguistas críticos, tais como Van Leeuwen (1997), Fairclough (1989, 2003), dentre outros, pelo fato de que na atribuição de papéis nestas representações pode haver discrepância ou incongruência entre os papéis gramaticais desempenhados textualmente e os papéis sociais desempenhados nas práticas em que estes atores se situam. Segundo Van Leeuwen (1997:187), tais representações podem deliberar quem receberá papel ativo ou passivo nas ações, podendo até redimensionar as relações sociais. Deste modo, a atribuição de papéis é ideologicamente significativa.

Ex 11: [Os criminosos] perguntaram a Márcia com quem ela queria ficar presa no quarto. Ela escolheu a filha de 13 anos. 
Ex 12: O médico-legista que examinou o corpo informa que o mais famoso navegador da atualidade, o grande campeão de iatismo mundial e o ídolo que chegou a ser condecorado pela rainha da Inglaterra, tomou dois tiros pelas costas.

Ex 13: Fernando recebia surras de cano, que era enrolado numa toalha molhada para evitar o aparecimento de hematomas em seu corpo.

Ex 14: No andar superior, deitada na cama, Vera Kuhn, morta, exibia um corte profundo na garganta (...) e três perfurações no tórax.

Os exemplos acima tipificam a incongruência entre papéis sociais e papéis gramaticais que os atores podem desempenhar na representação textual. Gramaticalmente, as vítimas, em cada situação, são sujeitos ou agentes gramaticais dos processos representados, tais como "escolheu", "tomou”, "recebia” e "exibia” pela posição que ocupam no nível da sentença; só que na verdade, a prática social revela que esses atores estão sujeitos ou submetidos ao poder de ação dos outros participantes, ou seja, os criminosos. Desse modo, as vítimas são pacientes porque recebem, sofrem os resultados ou efeitos dos processos representados, marcando assim, a discrepância entre representação textual e a realidade dos fatos.

No mesmo pensamento, Fairclough (2003:150) afirma que o significado da ativação e passivação é bastante transparente, isto é, o que se acentua quando atores sociais são ativados em uma circunstância ou processo é a sua capacidade de exercer uma ação agentiva, como também fazer com que as coisas aconteçam ou até mesmo poder de controlar pessoas. Por outro lado, quando passivados, o que se acentua nos atores sociais é a sujeição aos processos, sendo, portanto, afetados ou sofrendo os resultados das ações dos outros. 
As escolhas que o autor do texto faz para representar os processos e participantes, escolhas estas codificadas nas formas gramaticais da língua, são inúmeras e revelam uma percepção do mundo social em termos inclusive de identidades sociais. Em nosso corpus, os processos verbais e participantes (agente e paciente) estão em maior evidência.

$\mathrm{Na}$ circunstância dos crimes de morte, a análise dos dados demonstra que há uma assimetria total de poder entre vítimas e criminosos no modo como ocorre a distribuição de papéis e a representação linguística. Os criminosos são aqueles que atuam como agentes sobre as vítimas na maioria das vezes, seja material ou simbolicamente, através da violência. As vítimas, por sua vez, são quase sempre passivadas, e quando ocorrem de atuarem como agentes em relação a uma dada ação, esta ação diz respeito a sua rotina de vida pessoal ou pública, conduzindo o/a leitor/a a supor que, de algum modo, elas contribuíram para sua própria morte.

Notamos que essa representação, feita em termos lingüísticos, traz elementos que legitimam o exercício de papéis passivos para as vítimas e ativos para os criminosos no discurso da mídia, como por exemplo, as estruturas ativas (Ex 15: Os dois bandidos amarraram as vítimas na cama e as estupraram. Em seguida Alan deu uma profunda facada no pescoço da menina, mas quer convencer a polícia de que foi Marcelo quem ficou com o serviço pesado, liquidando Márcia a golpes de facão.), as estruturas passivas (Ex 16: Welson foi violentado, emasculado, teve o dedo da mão direita cortado e ainda foi asfixiado.), as nominalizações (Ex 17: De acordo com presidente do sindicato, Antônio Rodrigues da Silva, Lima fazia parte de uma lista de 24 pessoas marcadas para morrer no Pará por suas atuações em invasões de seis fazendas em Marabá e em Paraupebas.) e o apagamento da agência (Ex 18: O líder semterra Gilson de Souza Lima, 32, foi assassinado com tiro no rosto, na noite de sexta.). Esses elementos apontam tanto para a possibilidade da incongruência entre papéis gramaticais e sociais desempenhados pelos atores quanto para a percepção do autor sobre o mundo social que está 
sendo representado, no que diz respeito ao conhecimento, crenças e valores.

- Modalização - A modalização, especialmente em sua relação com a avaliação é bastante relevante para a construção de identidades sociais. Tanto a modalização quanto a avaliação são vistas em termos do que ou com o que o autor do texto se compromete quanto ao que é verdade, necessidade ou obrigação (modalidade), bem como no que diz respeito aos valores desejáveis e indesejáveis, ao que é bom ou ruim (avaliação). A questão é que aquilo com que as pessoas se comprometem quando enunciam é uma parte importante de como elas identificam a si próprias e aos outros no processo de construção de identidades sociais (Fairclough 2003:165).

No exemplo 19, “A vítima pode ter sido esfaqueada no pescoço. Provavelmente, foi arrastada logo em seguida para a sala de cirurgia da clínica”, o autor relata como a vítima foi assassinada. Ele podia ter escrito, por exemplo, "A vítima foi esfaqueada no pescoço e foi arrastada logo em seguida para a sala de cirurgia”. Contudo, a forma como o enunciado foi construído mostra um comprometimento menor do autor com a verdade da proposição, se comparado à segunda possibilidade. Deste modo, a diferença ou níveis intermediários entre as duas alternativas é justamente, uma diferença de modalização.

Vale ressaltar que geralmente, a tendência dos textos noticiosos quanto ao modo de enunciar é através de sentenças para representar verdades categóricas, caracterizando, assim, um discurso autoritário e não neutro. Essas sentenças, segundo Fairclough (2003:165), estão associadas às trocas de conhecimento e podem ser factuais (ex: PM mata dois no Pará), hipotéticas (ex: Os aliados do prefeito teriam tentado chantagear com fitas que comprovariam a pedofilia do prefeito.) ou preditivas (ex: Todos esses detalhes deverão ser investigados pelos policiais envolvidos na elucidarão da morte de Celso Daniel). 
No que diz respeito à investigação das ocorrências de modalização e sua relação com a avaliação, destacamos a modalização avaliativa, bastante frequente no corpus. Nos termos de Fairclough (2003:171), este tipo de modalização diz respeito aos modos explícitos e implícitos pelos quais os autores se comprometem com valores. No exemplo 20 “As revelações de Marcelo feitas à Isto É provam que permanece viva a herança dos anos de chumbo no Brasil, época em que o espancamento de presos fazia parte da rotina policial em delegacias e presídios”, o autor se refere ao fato de que ainda hoje, presos são torturados e mortos nos presídios e delegacias como no período da ditadura militar. A sentença "permanece viva a herança dos anos de chumbo no Brasil" avalia em termos do que ele considera "útil" e "importante", ou seja, denunciar a violência policial como um elemento que ainda faz parte da rotina das instituições carcerárias no país, que resulta muitas vezes na morte de presos. Deste modo, pressupõe-se que o que é assumido como desejável é o fim da violência desenfreada nessas instituições carcerárias.

É importante considerar que as formas de modalizar transcendem os marcadores tradicionalmente eleitos, talvez por isso a dificuldade de consenso neste assunto. Tais marcadores, enquanto formas linguísticas, dependem do contexto para entendermos que tipo de modalização desempenham. A partir da análise do corpus, percebemos que os verbos modais (Ex 21: "Eles [os policiais] não descartam a hipótese de que o assassinato pode estar relacionado a interesses econômicos contrariados pelo prefeito"), os tempos verbais hipotéticos (Ex 22: "Um adolescente que teria testemunhado o assassinato está sob proteção da polícia”), os adjetivos (Ex 23: “A imagem, chocante, é menos brutal que as manchas violáceas que se anunciaram durante meses, silenciosas, constantes e despercebidas, na pele enrugada de dona Luciana. Muito menos trágica que os sons da agressão ouvidos pelas outras duas empregadas e silenciados”.), os advérbios (Ex 19: "A vítima pode ter sido esfaqueada no pescoço. Provavelmente, foi arrastada logo em seguida para a sala de cirurgia da 
clínica”.) e as sentenças avaliativas (Ex 20: "Diante de tantas causas imprevisíveis, a governadora do Rio, Rosinha Matheus, considerou a morte da menina uma fatalidade. "É algo que acontece quando se está à caça de bandidos”, minimizou. Trata-se de uma declaração infeliz”.) são as formas mais comuns utilizadas para marcar as modalizações nos relatos de crime de morte.

O uso da modalização e das demais categorias representacionais que identificamos em nosso corpus, a saber, nomeação, categorização, a distribuição de papéis e a modalização, nada mais são do que formas convencionadas das quais jornais e revistas dispõem para guiar nossa interpretação e reação de determinado modo diante do relato de crimes de morte. Tais categorias são, portanto, reflexo das práticas sociais nos textos e não criações aleatórias ou independentes dos autores, que apontam para o modo como nossa sociedade identifica pessoas e grupos atribuindo-lhes uma identidade social.

\section{Considerações finais}

Perceber as identidades sociais como um dos efeitos construtivos do discurso constitui uma ferramenta importante para compreender como se dão as mudanças em nossa realidade social e cultural. Para isto investigamos como estas identidades são construídas no texto noticioso pelo seu importante papel na formação de opinião pública. Nesta perspectiva nos situamos no paradigma teórico-metodológico da ACD, que se preocupa em analisar os aspectos linguísticos e semióticos dos problemas sociais, percebendo o discurso como texto, ação, interação social, dialeticamente construído e elemento constitutivo da sociedade e da cultura.

Em nossa análise, observamos que a regularidade das categorias analíticas recorrentes funciona como recurso argumentativo, contribuindo assim, para a legitimação das representações de identidades sociais feitas no texto noticioso. Tais categorias ganham um status de 
normalidade enquanto modelos que assimilamos inconscientemente ao consumirmos notícias, quase sempre sem reflexão ou contestação dos usos da linguagem.

A utilidade desta análise crítica está, justamente, em colaborar com a formação de leitores/as mais críticos/as acerca dos usos ideológicos que se fazem da linguagem, nas mais variadas práticas discursivas e sociais, como é o caso da produção de notícias e reportagens. Esses/ as leitores/as estão totalmente envolvidos/as na articulação discursiva dos valores, crenças e estereótipos construídos e transmitidos no texto noticioso. Uma análise crítica do discurso da mídia pode corroborar com a mudança de posição desses/as leitores/as enquanto sujeitos passivos para agentes e intérpretes conscientes das estratégias de poder e controle utilizadas na construção das notícias e reportagens, sobretudo no que diz respeito à construção de identidades sociais de vítimas e criminosos.

Desde a seleção do fato, ou seja, do tipo de crime que merece ser noticiado, até a produção do texto em si, os autores, enquanto também agentes de práticas discursivas, revelam seu próprio posicionamento, valores e avaliação diante do que é representado através das categorias linguístico-discursivas que escolhem para construir a representação de identidades sociais dos atores envolvidos, ou seja, das vítimas e criminosos. Com isso, podemos afirmar que nenhum discurso, nem mesmo o discurso da mídia impressa, é neutro ou imparcial, sem um ponto de vista ou livre das impressões avaliativas do autor. Não podemos dissociar, portanto, produção linguístico-discursiva do que isso representa e reflete.

Recebido em: setembro de 2009 Aprovado em novembro de 2009 heribr@yahoo.com.br 


\section{Referências bibliográficas}

Bakhtin, M. Marxismo e filosofia da linguagem. São Paulo: Hucitec, 1992.

Bell; A.; Garrett, P. Media and discourse: a critical overview. In: (Eds.). Approaches to media discourse. Oxford: Blackwell, 1998, p. 1-20.

Bordieu, P. O poder simbólico. Rio de Janeiro: Editora Bertrand Brasil S. A., 1987. Caldas-Coulthard, C. R. News as social practice: a study in critical discourse analysis. Florianópolis: Editora da UFSC, 1997. (Advanced Research English Series, 1).

Clark, R. et al. Conscientização crítica da linguagem. Campinas: Editora da UNICAMP, 1996, p. 37-57. (Trabalhos em lingüística aplicada $n^{\circ} 28$ )

Dias, A. R. O discurso da violência: as marcas da oralidade no jornalismo popular. São Paulo: EDUC/Cortez Editora, 1996.

Duranti, A. Unites of participation. In Linguistic anthropology. Cambridge: Cambridge University Press, 1997, p. 280-330.

Fairclough, N. 1995. Media Discourse. London: Edward Arnold, 1995. . Language and power. London: Longman, 1989. . Political discourse in the media: an analytical framework. In Bell, A.; Garrett, P. (Eds.) Approaches to media discourse, Oxford: Blackwell, 1998, p. 142-162.

. Discurso e mudança social. Brasília: UNB, 2001. . Analyzing discourse: textual analysis for social research. London and New York: Routledge, 2003.

Fishman, M. Crime waves as ideology. Social Problems 25 (4): 531-543. 1978. Bell, A.; Garrett, P. (Eds.). Approaches to media discourse, Oxford: Blackwell, 1998.

Gumperz, J. (Ed.). Language and social identity. Cambridge: Cambridge University Press, 1982.

Kress, G.; Van Leeuwen. Reading images: The grammar of visual design. London: Routledge, 1996.

Lopes, L. P. M. 2002. Identidades fragmentadas: A construção discursiva de raça, gênero e sexualidade em sala de aula. Campinas: Mercado das Letras, 2002. 
Marcuschi, L. A.. A ação dos verbos introdutores de opinião. INTERCOM 64: 74-92, 1991

2002. Gêneros textuais: definição e funcionalidade. In: Dionisio, A. et al (Orgs.) Gêneros textuais \& ensino. Rio de Janeiro: Lucerna, 2002.

Ochs, E. Constructing Social Identity: a language socialization perspective. Research on Language and social interation, 26 (3):287-306, 1993.

. Linguistic resources for socializing humanity. In: Gumperz, J.; Le-

vinson, S. (Eds.) Rethinking linguistic relativity. Cambridge: Cambridge University Press, 1996, p. 406- 437. (Studies in the social foundations of language 17)

Phillips, L.; Jorgensen, M. Discourse analysis as theory and method. London: SAGE, 2002.

Rajagopalan, K. O conceito de identidade em lingüística: é chegada a hora para uma consideração radical. In: Signorini, I (Org.). Linguagem e identidade: elementos para uma discussão no campo aplicado. São Paulo: Mercado de Letras, 1998, p. 21-45.

Signorini, I. (Org.). Linguagem e identidade: elementos para uma discussão no campo aplicado. São Paulo: Mercado de Letras, 1998.

Tistscher, S. et al. Methods of text and discourse analysis. London: SAGE, 2003. Van Dijk. T. Mediating Racism: the role of the media in the reproduction of racism. In Wodak, R. (Ed.). Language, power and ideology. Amsterdam: Benjamins, $1987^{\mathrm{a}}$.

.Critical discourse analysis. In Schiffrin, D. et al. (Eds.) The handbook of discourse analysis. London: Blackwell, 2004.

Van Leeuwen, T. A representação dos atores sociais. In: Pedro, E. (Org.). Análise crítica do discurso. Lisboa: Caminho, 1997, p. 169-222. 